\title{
Teologiese tipologie: 'n Homiletiese sleutel vir die prediking van die
}

\section{Ou Testament}

Jan $J$ van der Walt, Potchefstroom

\section{ABSTRACT \\ Theological typology: A homiletic key for preaching on the Old Testament}

The Old Testament is historical, has its own character and together with the New Testament it is the one Word of God. Homiletics indicate which rules should be applied to preach the Old Testament correctly. In this article typology as a homiletic key is dealt with - a key to facilitate the way in which exegesis can be processed into preaching. Although the use of typology frequently lapses into subjectivism and fantasy, its value for preaching can not be denied. It helps to gain insight in the self-fulfilling activity of God but not in the human instruments through which $\mathrm{He}$ acts. As directives and controls for theological typology in the preaching of the Old Testament, three formulas from the New Testament are dealt with: fulfilment which accentuates God's faithfulness, purpose which accentuates God's council and fulness which, in an theocentric way, shows that the unity and continuity of history is given in God.

\section{DIE TIPOLOGIESE PREDIKING VAN DIE OU TESTAMENT GAAN NIE OOR MENSE NIE}

Daar is 'n baie "maklike" en daarom verleidelike manier om uit die Ou Testament te preek deur 'n mens, van wie geskrywe word, tot 'n tipe of voorbeeld aan die gemeente voor te hou. Op hierdie manier word die sentrale boodskap van so 'n preek: "word 'n Rut": "wees nie 'n Esau nie". Op dieselfde wyse sou ook oor Calvyn, Vader Kestell of Lenin gepreek kan word: Daarom is dit duidelik dat prediking oor menslike tipes nie Bybelse prediking is nie, al kom die mense in die Bybel voor.

Von Rad (1974:14) het uitgewys dat die Bybel dikwels geen oordeel uitspreek oor menslike handelinge nie, waaruit afgelei behoort te word "dass er es überhaupt nicht so eilig haben soll, über die Menschen in diesen Erzählungen zu urteilen. Vielmehr soll er auf das achten, was von Gott hat an diesen Menschen geschieht". Hierin klink inderdaad "geen uitgediende waarskuwing" nie (De Klerk, 1977:22). Bright (1967:195) spreek ook kommer uit: "Now it is assuredly true that we want no allegorizing or spiritualizing of that details of that Old Testament narrative, no moralizing from its various characters. But is this not spread broad enough?" Daar is geen getuienis om tans op Bright se vraag ontkermend te antwoord nie (vgl Van der Walt, 1985:41-63). 
Die stelling van Gordon Spykman, in 'n lesing te Potchefstroom voor die Gereformeerde Teologiese Vereniging, vat die rede vir die oorlewingskrag van preke oor mense pragtig saam: "It is so nice and easy, and people love it so much". Maar die preke oor mense bring mee dat 'n arm evangelie aan die gelowige/ongelowige gepreek word in plaas van om die lewende God te verkondig (vlg Hand $17: 23(\mathrm{~b}) \cdot 31$ ).

\section{VOORVERONDERSTELLINGS WAARVAN IN DIE ARTIKEL UITGEGAAN WORD}

Die belangrikste voorveronderstellings vir die prediking van die $\mathrm{Ou}$ Testament is sy eenheid met die Nuwe Testament, want buite die eenheid is die Ou Testament irrelevant vir die Christen en dus ook nie preekbaar nie. Op die eenheid - een woord van God - van Ou Testament en Nuwe Testament gaan hierdie artikel gevolglik nie in nie.'

Die eenheid van Ou en Nuwe Testament is in die prediking van die openbaring van God onontbeerlik (vgl Schmidt, 1987:449; Lampe 1956:10). Maar in die eenheid bly dit nog 'n ou en 'n nuwe Testament wat in die regte verhouding tot mekaar as een Woord van God gepreek moet word. Die twee-eenheid beteken dat die Ou Testament nie verklaar mag word asof die geboorte van Jesus Christus nie 'n nuwe historiese feit is nie. Die historisiteit van Ou en Nuwe Testament dien in hierdie artikel as onaantasbare voorveronderstelling (vgl Von Rad, ${ }^{2}$ 965:357-358; Bright, 1967:78) . Die eie van die twee testamente is ook 'n voorveronderstelling wat nie toelaat dat die Ou Testament vernuwetestamentiseer word nie (vg) Helberg, 1983:28; Marshall, 1980:8; Heyns, 1973:6; Bright, 1967:209).

Die voorgaande voorveronderstellings maak dit noodsaaklik dat die Homiletiek sekere reèls of merkers moet aandui vir die korrekte prediking van die Ou Testament, en die onderskeie merkers of reels vorm dan die sleutelbaard (HAT, 1972:785; vgl Van der Walt, 1988:492) vir tipologie as 'n sleutel.

\section{TEOLOGIESE TIPOLOGIE AS EEN VAN DIE SLEUTELS VIR DIE PREDIKING VAN DIE OU TESTAMENT}

Die herwaardering van die tipologie blyk uit die woorde van Versteeg (1977:19): "Terecht zegt Berkhof, dat de typologie het dominerende hermeneutische principe in het Nieuwe Testament is". Die bedoeling is nie om in hierdie artikel 'n eksegeties-hermeneutiese' ${ }^{3}$ sleutel te soek nie, maar om 'n homiletiese sleutel te soek (vgl Bright, 1967:92), en met die sleutel word bedoel die wyse waarop eksegese tot preek verwerk word, want "prediking, krachtens haar wezen verkondiging van Gods Woord, is iets anders dan Schriftverklaring" (Vriezen, 1966:146). Verskillende belangrike "relaties" tussen Ou en Nuwe Testament bepaal die prediking uit die Ou Testament : tipologie, voorbereiding, gelykheid en teenstelling (Vriezen, 1966:145, 146). Die verhouding tussen die Testamente is dus 'n "gedifferentieerde" (Vriezen, 1966:146) verhouding. Tipologie word deur Vriezen (1966:145) geevalueer as "deze zeer bijzondere en uiterst beslissende" differensiasie in die prediking van die Ou Testament. Uitgaande van die differensiasie word tipologie in hierdie artikel 
ondersoek as een van die belangrikste homiletiese sleutels vir die prediking van die Ou Testament. Oor die tipologie in die Homiletiek is baie min gepubliseer. ${ }^{*}$

Verkeerde tipologie (vgl Holwerda, 1974:112-113 en Bright. 1967:81) het al onberekenbare skade aan die geloofslewe van mense gedoen. Die misbruik en mistasting is meestal in gereformeerde kringe nie die resultaat van prinsipiële nadenke en beslissing nie, maar juis die teendeel, naamlik 'n gebrek aan prinsipiële besinning en 'n produk van onbeholpenheid. Vriezen (1966:102) waarsku daarteen om tipologie as "een soort wichelroede" oor elke teks te hou sodat die twee Testamente mekaar se "spiegelbeeld vormen". Bright (1967:84) waarsku op sy beurt: "But such interpretations are hard to control, quick to lapse into subjectivism and fantasy, and too frequently did so lapse". Tiperend van die "lapse" is die uitspraak op 'n preekstoel: "dit staan nou nie hier nie, maar ons kan dit goed indink" - en dan word wat "ingedink" is die basis van die preek. Daarom het ' $n$ vrees ontstaan vir tipologie in prediking (vgl Bright, 1967:84).

Tog is die betekenis van tipologie vir die prediking nie te ontken sonder ernstige gevolge nie. Sal so 'n ontkenning nie die Ou Testament afskryf as oergeskiedenis en irrelevant vir Christelike prediking en die Homiletiek laat terugval op Marcion nie? (vgl Bright, 1967:84, 194). Daarom word 'n homiletiese sleutel vir die prediking van die Ou Testament nodig geag.

Die prediker is geheel en al afhanklik van die Heilige Gees wat hom in sy werk verlig. Die treurige feit is dat 'n prediker Hom kan weerstaan (Hand $7: 51$ ) en selfs kan uitblus (1 Tess $5: 19$ ) as hy die Skrif verkeerd gebruik of selfs misbruik of wanneer hy daaroor heers met sy verbeelding.

Die toets vir 'n sleutel sal wees of en hoeveel dit bydra tot kontrole teen degenerasie. Daarop is die sleutel wat aangebied word gerig, sonder om te kenne te gee dat dit volledige kontrole waarborg.

Die degenerasie (vgl Trimp, 1986:56) van die tipologie in prediking wat 'n mens (in die Skrif genoem) verhef tot tipe sodat God op die agtergrond geplaas word, het tipologie as homiletiese sleutel onder ernstige verdenking gebring. Prediking moet die mens se geloof rig op God (vgl Hevns. 1973:8-10, 15: Van der Walt, 1988:486-511). Daar is tans weer ' $n$ beweging om tipologie vrugbaar te maak in prediking uit die Ou Testament (vgl Brown, 1976(3):9(16). Om in hierdie artikel die misbruik van die gebruik te onderskei, word van die korrekte tipologie in die prediking gepraat as teologiese tipologie.

\section{TEOLOGIESE TIPOLOGIE BERUS OP DIE ONVERANDERLIKE TROU VAN GOD}

Patrick Fairbain' (1876:8) het al gesê die doel van tipologie is dat 'n verklarende fondament (vgl Bright, 1976:92: "typological interpretation") gelê moet word vir die prediking van die Ou Testament. Daarvoor is nodig om die Skrifte vanselfsprekend as histories waar te aanvaar want anders het tipologie geen fondament om op te staan in prediking nie. 
Fairbain (1876:229) sê tipologie stel ons in staat om insig te kry in hoe en waarom God handel en nie in die instrumente (die mense) deur wie Hy handel nie. Die Ou Testament is nie 'n handboek vir Psigologie nie, maar openbaringsgeskiedenis van God in sy heilshandelinge met mense in die geskiedenis (vgl Van der Waal, 1974:229; Goppelt, 1939:227; Von Rad, 1965:364).

Goppelt (TDNT VIII:251; vgl Schmidt, 1987:442) dui 1 Kor $10: 6,11^{6}$ aan as locus classicus vir tipologie in die prediking. Die Ou Testament word in Nuwe Testamentiese prediking tipologies gebruik. Uit 1 Kor $10: 6$, 11 kan nie afgelei word dat "human situations are typical" (Bright. 1967:207) nie. Hierdie dinge (v. 6) verwys na wat voorafgaan in v. $1-5$. In hierdie verse word God se handeling (vgl Wolff, 1982:43) met Israel in die Ou Testament aangehaal. Die "self-fulfilling activity of God in concrete human history" (Brown, 1976(3):906) is die inhoud van hierdie tipologiese prediking. Schmidt $(1987: 442,443)$ vat die betekenis van 1 Kor $10: 6,11$ soos volg saam: die "Grundannahme" in die gebeurtenisse wat die Ou Testament meedeel, en in die gebeurtenisse wat die Nuwe Testamentiese gelowiges ervaar, is dat "in beide Geschehnissen wirkt derselbe Gott .. . So bewahrt typologische Betrachtung im Ansatz eine Sinn für Geschichte". Pop (1978:204) gaan te ver as hy tupos verstaan as foto, maar sien tog die betekenis van 1 Kor $10: 6,11$ reg as hy sè dat wat hulle "oorgekom" het vir ons tipologies is. En in wat hulle oorgekom het, is die handelinge van God bepalend.

Die prediking vir die eerste Christene het nou aangesluit by die geskiedenis en het die Evangelie histories-verankerd gehou (vgl Jonker, 1917:47, 111; Bright, 1967:78) . Hierdie teologies-tipologiese teruggryp op die geskiedenis het dus 'n "funderende funksie" (Van der Waal, 1974:228; Wolff, 1982:46).

In hierdie teologiese sin kom tipologie ook voor in die Nuwe Testamentiese prediking in 0.a. Rom 4, Gal 3 en 1 Pet $3: 12$. Die Ou Testament self bevat verskeie voorbeelde van tipologiese terugverwysing na die geskiedenis. Dit kom voor in historiese boeke (Eks 3:5; Deut $4: 9$; Jos $1: 5 ; 24: 1$-15), profetiese boeke (Jes $40: 21-25 ; 43: 1$ - 4; Eseg 55 : 5 - 9; Hos $11: 7)$ en Psalms $(78,94,95,105,107,110)$.

Teologiese tipologie kan dus aanvaar word as een van die sleutels om uit die Ou Testament te preek. Om aan die gevare van valse tipologiese prediking te ontkom, gee die Nuwe Testament ons onder meer drie punte aan die sleutelbaard: vervulling (pleres), voltooiing (teleios) en voleinding (eskatos). Schmidt (1987:438, 442) praat van "Verheissung, Erfullung, Unabgeschlossenheit". Daar is inderdaad rede om "behutsam" (Schmidt, 1987:437) gebruik te maak van tipologie in die prediking uit die Ou Testament.

\section{RIGLYNE VIR TEOLOGIESE TIPOLOGIE IN DIE PREDIKING VAN DIE OU TESTAMENT}

Kontroles (vgl Bright, 1967:80, 93, 194) vir die prediking uit die Ou Testament is nie net wenslik nie, maar noodsaaklik. Daarom word die aandag nader gevestig op kontroles wat die Nuwe Testament aandui. 


\subsection{Die vervul-formule}

Die Ou Testament word in die Nuwe Testament vervul. Die woorde "Dit het gebeur sodat die woord wat die Here deur sy profete gespreek het, vervul sou word" wat herhaaldelik in Matteus voorkom, vorm skering en inslag van die hele Nuwe Testament (vgl Matt $1: 22,2: 15,17,23: 4: 14$; $8: 17 ; 12: 17 ; 13: 35 ; 21: 4 ; 27: 9,35$; Mark $1: 15$; Luk $4: 21 ; 21: 22,24 ; 22: 16$; $24: 44 ;$ Joh $7: 8 ; 15: 25 ; 18: 9$; Hand $3: 18 ; 13: 32 ;$ Kol $1: 24,25)$.

Die woord vervul beteken "om vol te maak", te "vervolmaak" (Arndt. 1957:677). Dit kan betrekking hẽ op 'n periode of 'n profesie of 'n belofte. "Vervul" word meestal in die passief gebruik en dui aan dat God die handelende Persoon is, of dat sy wil vervul word. Hierdie vervulling geskied deur wat Grod in Christus en in die Gees doen (vgl Helberg, 1973:53). God vervul sy Woord, die Wet en die Profete (Matt $5: 17$ ) deur dit voluit te aktualiseer (Hand $3: 18 ; 13: 27$ ). Teologiese tipologie dui aan "the selffulfilling activity of God in concrete human history (Brown. 1976(3):906). Die vervulling in die Ou of Nuwe Testament gee meer van die selfopenbaring, en hierdie meer is 'n openbaringshistoriese en eskatologiese meer (vgl Helberg, 1983:53; Schmidt, 1987:441).

So word wat God in die pasga gedoen het, vervul in die nagmaal, die sakrament van Jesus se dood en lewe, terwyl die maaltyd van lewensgemeenskap met God in die voleinding ( Luk 22:16) die finale vervulling, vol-making van die pasga is. Wat God in die pasga gedoen het, is tipologies van die nagmaal en die nagmaal is tipologies van die bruilofsmaal van die Lam en sy bruid.

So is teologies-tipologiese prediking uit die Ou Testament kontroleerbaar met die vraag na die vervulling in die Nuwe Testament; sonder vervulling is daar nie tipologie nie. Die vervullingsgedagte beperk tipologie in die prediking tot God se handelinge. Dan bly geskiedenis onverswak werklike gebeurtenisse. Daarom kan Versteeg (1977:19) die onderskeid tussen tipologie en allegorie skerp onderskei: vir allegorie het geskiedenisfeite geen betekenis nie, want dit gaan in allegorie om die sogenaamde "diepere betekenis". By die tipologie word die werklikheid van die geskiedenis in die prediking voluit vasgehou (vgl Trimp, 1986:51). Selfs die sogenaamde allegoriese prediking van Paulus in Gal 3 en Rom 4 is gefundeer op "een theologie der geschiedenis, die uitgaat van de vervulling der beloften in Christus" (Versteeg, 1977:19). Lammens (aangehaal deur Versteeg, 1977:19) gee 'n helder omskrywing: die tipologie wil laat uitkom "de in de geschiedenis werkzame constante van de trouw van Jahwe die Zijn verbond gedenkt en Zijn ene heilswerk voortzet in telkens nieuwe daden, die de vroegere overtreffen". S6 kan die prediking lyne trek ("typological interpretation" - Bright. 1967:92) vanuit die Ou Testament na die Nuwe Testamentiese Christelike gemeente (gelowige).

In die teologies-tipologiese prediking gaan dit nie daarom of iets "uitkom" (soos 'n voorspelling - vgl Helberg. 1983:100) nie, maar om vervulling, die vol-ler-wording van die trou van God. Die trou van God wat die Ou Testament openbaar en die trou van God wat aan die gemeente gepreek word, is een en dieselfde trou van een en dieselfde God. Daarom 
kan die Ou Testamentiese gegewens in hulle eie betekenis in 'n preek verkondig word aan 'n Christelike gemeente. Die teologiese tipologie preek die Ou Testamentiese Godsopenbaring in die lig van die Nuwe Testamentiese vervulling, en die konstante is "de konstante van de trouw van God" (Versteeg, 1987:21). Dit beteken "die Ou Testament moet in sy geheel deur die Nuwe Testament belig word en so ook die Nuwe Testament deur die Ou Testament. Die twee Testamente staan nie sonder meer as A en B langs mekaar nie, maar as ouere teenoor nuwere wat tog albei geldig is. Die Ou Testament bly egter geldig deur dood en opstanding heen, saam met Jesus Christus die mensgeworde Woord, en die Nuwe Testament ontstaan uit die opstanding van die mensgeworde Woord. Hy maak die Ou Testament die Oú Testament en die Nuwe Testament die Núwe Testament. Hy maak die twee tegelykertyd 'n eenheid"' (Helberg, 1983:99). Immers, die trou van God kulmineer in Jesus Christus (Rom $5: 1$ - 11).

In die sentrum van die teologiese tipologie in 'n preek staan die selfopenbaring van God: Ek is wat Ek is (Eks $3: 14$ )

\subsection{Die doel-formule}

Teleo dui die bereiking van 'n doelwit aan. Die werkwoord teleo word verskillende kere gebruik om die vervulling van die Ou Testament in die Nuwe Testament aan te dui : (Luk $18: 31 ; 22: 37$; Hand $13: 29$; Joh $4: 34 ; 13: 1 ; 17: 4 ; 19: 28$ ).

Die gebruik van teleo sê dat daar ' $n$ plan is waarvolgens gehandel word om die doel, wat verwerklik moet word, te bereik. In Lukas 18 : 31 sê die futurum (telesthesetai) wat verseker sal gebeur: "en alles wat deur die profete geskrywe is, sal aan die Seun van die mens vervul word" (1953-vertaling). Die passief van telesthesetai (Luk $18: 31$ en $22: 37$ ) lê die klem op wat gebeur en nie op die handelende instansie nie. Teleo word aktief gebruik om aan te dui dat die Jode in hulle vyandskap teen Jesus God se raad tot sy doelwitte volbring (Hand $13: 29$ ). Teleo dui dus aan dat met die vervulling ook 'n doelwit bereik is. So het Jesus sy "eie mense" tot die einde (eis telos) liefgehad (Joh 13:1), en die "einde" dui Hy aan met die kruiswoorde "Ek het dors" en "Dit is volbring" (Joh $19: 28,29$ - tetelesthai). Die doel waarvoor Jesus gekom het (Joh $4: 34 ; 17: 4 ; 19: 28$ ) is verwesenlik "sodat die Skrif vervul (teleiothei) sal word.

In regstreekse verbintenis met die teologies-tipologiese prediking uit die Ou Testament lê 1 Korintièrs $10: 11$ klem op die telos, die doelwit, van die gedeelte in die Ou Testament wat in die Christelike tyd (voorlopig) bereik is: "Maar al hierdie dinge het hulle oorgekom as voorbeelde en is opgeskrywe as 'n waarskuwing aan ons op wie die eindes van die eeue gekom het"' (vgl Fisher, 1975: 158).

Jesus bring die Raad van God tot verwesenliking, volbring die doel daarvan, doen alles wat van Hom in die Ou Testament tipologies gesê is. In Lukas $24: 25-27$ leer Hy hierdie magtige waarheid aan die Emmausgangers (vgl Greijdanus, 1941:1186-1187). Christus moes (edei) die lyde van die kruis (en alles daaromheen) ly. "Moes" verwys na die doel 
van God in sy Raadsplan. Daar moet op gelet word dat Jesus nie sê die Skrifte het op Hom alleen betrekking sodat Hy alleen in die ganse Ou Testament tipologies teenwoordig is nie. Die woorde ta per eautou dui aan dat alles wat Jesus moes ly in die Ou Testament tipologies aangedui word, maar alles in die Ou Testament sien nie alleenlik net op Jesus nie. Ten minste word die uitstorting van die Heilige Gees ook as vervulling van die Ou Testament gepreek (Hand $2: 4,16,17$ ). En dit is die Vader wat sy werk volmaak (Hand $2: 22,23 ; 17: 30,31 ; 1$ Kor $15: 24-28$ ).

Teologies-tipologiese prediking uit die Ou Testament kan dus gekontroleer word met die vraag: watter doelwit van God word bereik?

\subsection{Die voleinding-formule}

Die vervulling en die doelbewerking reflekteer steeds na die eskatologiese voleinding. Wat aan die kruis met Jesus gebeur en wat Hy daar volbring om God se Raad te verwesenlik, eindig nie daar nie. Daarom mag die tipologiese prediking van die Ou Testament (en die Nuwe Testament) nie die kruis, of kruis en opstanding, preek as die finale einde nie. Die tipologie staan van Genesis tot Openbaring oop na die voleinding (vgl Trimp, 1986:50; De Klerk, 1977:35; Schmidt, 1987:438 - 440; Bingle, 1989:1 - 441).

1 Kor 15 : 22 - 28 gee hieraan duidelik uitdrukking. Paulus verbind hier die doelbereiking (telos) daaraan dat Christus die koningskap aan God die Vader oordra nadat Hy alle bose magte vernietig het. Voor die voleinding moet (dei) Christus as koning heers totdat die Vader al sy vyande aan Hom onderwerp het. Hierdie "objectief eschatologische stuk" (Greijdanus, 1941:515) openbaar Christus se taak na kruis en opstanding, d.i. die oopheid na vore van tipologie in vervulling en doelwitbereiking. Dit is vir ons belangrik om daarop te let dat Paulus hier gebruik maak van Psalm 110. Greijdanus (1951:516) sẽ dit hang saam met "met" (dei - v 25) dus met die Raad van God (vgl Matt 22: 44: Luk $22: 37$; Joh $13: 1$ ). Daarom word die daad van die Vader vermeld. Die ganse Bybel openbaar die werk van God as 'n ekonomie van die Drie Persone in die eenheid van die enige God. Die dood en opstanding van Christus word voltooi, en die volle doel bereik as die dood in die eskaton (v 26) vernietig word. Maar nog is dit nie finaal nie. Die Seun aan wie alles onderwerp is - selfs die dood, die laaste (eskatos) vyand - sal Homself nog onderwerp aan die Vader. Dan is die ewige vrederaad voltooi en die versoening tot sy volle telos gebring. Sy "koningswerk is afgeloopen by to telos" (Grosheide, 1932:520).

Versteeg (1971:520) het in sy proefskrif duidelik aangetoon dat die verhouding van die opgestane Christus en die Heilige Gees eskatologies bepaald is. In die opstanding van Christus is die eskaton gerealiseer en deur die Gees word die eskaton gerealiseer (onderstreping bygevoeg) . Die twee is vanselfsprekend nie los te maak van mekaar nie.

Dan kom God tot sy eer want al die verset is deur die werk van Christus en die Gees uitgeskakel.

God is dan alles.

En Hy is alles in almal. 
Hy is die drie-enige God (1 Kor $15: 28$ - ho Theos).

Tipologiese prediking is nie Christosentriese prediking met Christus as sentrum nie, want Christus is Middelaar maar nie sentrum nie. "Sentrum" durf nie meer sê as die Bybelse "Middelaar" nie.

Teologies-tipologiese prediking is teosentriese prediking wat die ekonomie van die Drie-eenheid ten volle verdiskonteer (vgl Ridderbos, 1966:469).

Tipologiese prediking word deur die voleinding (eskatos) gedwing om teosentries te wees. Greijdanus (1970:158) gee hieraan duidelik uitdrukking ivm prediking oor Gideon: "That is the first and basic parallel: the same God, then and now. The theosentric explication, therefore, is the first step of application. The unity and continuity of history is given in God: He is one; the history He makes is one; the Kingdom He establishes is one; the Church He creates is one - one throughout the ages. And so it is possible to establish parallels between what God did then and what God does today, and even between the people through whom God worked then and the people through whom the same God will work today".

Die geldigheid van teologies-tipologiese prediking is dus kontroleerbaar met die vraag: wat is die eskatologiese gerigtheid?

SLOTSOM

Teologies-tipologiese prediking gee volle erkenning aan die eiesoortigheid en historisiteit van die Ou Testament in sy eenheid met die Nuwe Testament. Die Bybel is die een Woord van die een God wat Homself ontvouend openbaar as die Drie-enige God wat trou bly aan Homself in die ekonomie (huishouding/samewerking) van die Drie Persone sodat een nooit swaarder ("swaartepunt") of meer sentraal ("sentrum") as die ander is nie. Teologiese tipologie lei ons in die prediking vanuit die Ou Testament deur die Nuwe Testament op weg na die gemeenskap met God wat vol en voltooi en voleindig sal wees in die nuwe hemel op die nuwe aarde: "en God self sal by hulle wees as hulle God" (Op 21:3).

\section{VOETNOTAS}

1. Vergelyk oor die eenheid die argument van verskeie skrywers: In die Skriflig: L Floor, 18/69, 1984 en 14/55, 1980; WH Velema, 15/60, 1981: C Trimp, 19/75, 1985. Daar is ook die uitvoerige werk van DL Bakker: Two Testaments, One Bible (1976). Verder PA Verhoef: The Relationship between die Old and the New Testament (1970). Ook die artikel van JA Heyns in Tydskrif vir Geesteswetenskappe, 13/1, 1973. En John Bright: The Authority of the Old Testament, (1967:193, 205-207).

2. Ondanks sy standpunt dat die Ou Testamentiese geskiedenis "already in some measure interpreted" is, is die Ou Testament tog vir Von Rad "a history book". Vir evaluering van Von Rad vgl Helberg, 1983:26, 27; Vriezen, 1966:145.

3. Oor 'n hermeneutiese bespreking van tipologie kan Vriezen, 1966:145, 146 voetnoot 2: Von Rad. 1965:366-368 en Helberg, 1976:26-31 geraadpleeg word.

4. Volgens Religion Index. Periodicals American Theological Library Association. 1981-1987 het daar oor die homiletiese aspek geen artikel verskyn nie; en volgens 'n rekenaarondersoek van die Ferdinand Postma Biblioteek. PU vir CHO, het daar geen verhandeling of proefskrif in Suid-Afrika oor tipologie verskyn nie

5. Hy word ook hoog geag deur John Bright (1967:84, voetnoot 57): "proper over against improper use of typology."

6. Dit is opmerklik dat so min aandag aan hierdie teks gegee word deur ander skrywers oor tipologie. 


\section{BIBLIOGRAFIE}

Arndt, WF \& Gringrich. IW. 1957. A Greek-English Lexicon of the New Testament and other Early Christian Literature. Chicago: University Press.

Barret. CK. 1968. Black's New Testament Commentaries. The first Epistle to the Corinthians. London: Adam \& Black.

Bingle, PW. 1989. Coram Deo: die betekenis van die eskatologie vir die prediking. Potchefstroom. (Proefskrif ThD - PU vir CHO).

Bright. J. 1967. The Authority of the Old Testament. London: SCM Press.

Brown, C (red). 1976. Dictionary of New Testament Theology, Vol. 2 \& 3. Exeter: Paternoster.

De Klerk, JJ. 1977. Prediking. Pretoria: NG Kerk-boekhandel.

Fairbain, P. 1876. The Typology of Scripture: viewed in connection with the whole series of the Devine Dispensations. Edinburgh: T \& T Clark.

Fisher, F. 1975. Commentary on $1 \& 2$ Corinthians. Waco: Word Books.

Floor, L. 1980. Die Hermeneutiek van Calvyn. In die Skriflig 14/55. 13-20 September.

Goppelt. L. 1939. Typos. Die typologische Deutung des älten Testaments in Neuen. Gutersloh: Bertelsman.

Goppel, L. 1979. Theological Dictionary of the New Testament. Michigan: Eerdmans Sv Tupos : $246-259$.

Goudge. HL. 1926. The First Epistle to the Corinthians. London: Methuen.

Greijdanus. S. 1970. Sola Scriptura. Kampen: Kok. 1941. Kommentaar op het Nieuwe Testament. Het Heilige Evangelie naar de beschrijving van Lukas II. Amsterdam: Bottenburg.

Grosheide, FW. 1932. Kommentaar op het Nieuwe Testament. De eerste brief van de apostel Paulus aan de kerk te Korinthe. Amsterdam: Bottenburg.

Helberg. JL. 1976. Ou Testamentiese Teologie in verleentheid? Wetenskaplike Bydraes van PU vir CHO. Reeks A: Geesteswetenskappe $\mathrm{nr}$. 25.

Helberg, JL. 1983. Verklaring en Prediking van die Ou Testament. Potchefstroom: Potchefstroom se Teologiese Publikasies.

Heyns, J. 1973. Historisiteit van en in die Bybel. Tydskrif vir Wetenskap en Kuns, $13 / 3: 3-20$.

Jonker, H. 1917. Liturgische Orientatie. Gesprekken over de eredienst. Pretoria : NG Kerkboekhandel.

Lampe. GWP. 1956. Studies in Biblical Theology no. 22. Essays on Typology. London: SCM Press. 9-38.

Marshall, IH. 1979. How do we interpret the Bible today. Themelios, 5/1:7-12.

Morris, L. 1960. The First Epistle of Paul to the Corinthians. Leicester: Inter-Varsity Press.

F 、 FJ. 1978. De eerste brief van Paulus aan de Corinthiers. Nijkerk: Callenbach.

Ridderbos, H. 1966. Paulus. Ontwerp van zijn theologie. Kampen: Kok

$\boldsymbol{c}_{\text {mit, }}$ D. 1988. Woord teen die lig B/1. Hoe verstaan ons wat ons lees? Kaapstad: NG Kerk-Uitgewers.

Schmidt, WH. 1987. Ansatze zum Verstehen des Alten Testaments. Evangelische Theologie, 47/42:436-459.

Stott, JRW. 1982. I believe in preaching. London: Hodder and Stroughton.

Trimp, C. 1986. Heilsgeschiedenis en prediking. Kampen: Van den Berg.

Van der Waal, C. 1974. Enkele opmerkings oor tipologie. Ned. Geref. Tydskrif XV/1: 225-235

Van der Walt, JJ. red. 1985. God aan die Woord. Potchefstroom: Diakonologie 1988. God werk deur die prediking in die geloofslewe: 'n Homiletiese sleutel vir die prediking. Koers 53(3):486-511.

Versteeg, JP. 1977. De Oudtestamentische citaten in het Nieuwe Testament, met name in het evangelie naar Matteus. In die Skriflig, 11/42:10-24. 1971 Christus en de Geest. Kampen: Kok.

Von Rad, G. 1965. Old Testament Theology II. The Theology of Israel's prophetic traditions. Vertaler DMG Stalker. London: Oliver and Boyd.

Vriezen, ThC. 1966 . Hoofdlijnen der Theologie van het Oude Testament. Wageningen: Veenman.

Wolff. C. 1982. Der erst Brief des Paulus an die Korinther. Zweiter Teil. Berlin: Evangelische Verlagsanstalt. 